\title{
Efeito do inóculo, período de molhamento foliar e do estádio fenológico do feijão-caupi no desenvolvimento da mela
}

\author{
Kátia de Lima Nechet \& Bernardo A. Halfeld-Vieira \\ Embrapa Meio Ambiente, 13820-000, Jaguariúna, SP, Brasil \\ Autor para correspondência: Kátia de Lima Nechet, e-mail: nechet@cnpma.embrapa.br
}

\begin{abstract}
RESUMO
A mela, causada pelo fungo Thanatephorus cucumeris (anamorfo Rhizoctonia solani grupo de anastomose 1 IA) é uma das principais doenças do feijão-caupi (Vigna unguiculata) na região norte. Não há estudos sobre o efeito de parâmetros epidemiológicos no desenvolvimento da doença em condições controladas. Os objetivos deste trabalho foram definir efeito do tipo e da concentração de inóculo de $R$. solani, do(s) estádio(s) do feijão-caupi suscetível(is) e do período de molhamento foliar na severidade da doença em casa-de-vegetação. No primeiro experimento testou-se o efeito do tipo de inóculo [fragmentos de micélio (fgm) ou microescleródios]; no segundo experimento testou-se as concentrações de $0,10^{3}, 10^{4}, 10^{5}$ e $10^{6} \mathrm{fgm} \cdot \mathrm{mL}^{-1}$; no terceiro experimento as plantas foram submetidas aos períodos de $0,6,12,24$ e 48 horas de câmara úmida após a inoculação e no quarto experimento inoculou-se plantas nos estádios de folhas primárias, folhas trifoliadas, de floração e de enchimento de vagens. Observou-se que, para desenvolvimento de alta severidade da mela do feijão-caupi as plantas devem ser inoculadas no estádio de flores abertas na concentração de $10^{6}$ fgm. $\mathrm{mL}^{-1}$ e submetidas a seis horas de molhamento foliar. Estes parâmetros podem ser utilizados para definição de uma metodologia de inoculação de $R$. solani em feijão-caupi em condições controladas.
\end{abstract}

Palavras-chave: Rhizoctonia solani, Thanatephorus cucumeris, Vigna unguiculata, epidemiologia, feijão-de-corda.

\begin{abstract}
Effect of inoculum, leaf wetness period and cowpea phenological states on web blight development

Web blight caused by the fungus Thanatephorus cucumeris (Rhizoctonia solani anastomosis group 1 IA ) is one of the most important diseases of cowpea (Vigna unguiculata) in the north of Brazil. There is no information about the effect of epidemiological parameters on development of the disease under controlled conditions. The aims of this work were to identify the type and inoculum concentration of $R$. solani, the susceptible phenological states and the leaf wetness periods for disease development in greenhouse conditions. In the first study we tested the use of mycelia fragments $(\mathrm{mf})$ and sclerotia as source of inoculum; in the second experiment, the effect of different inoculum concentrations $\left(0,10^{3}, 10^{4}, 10^{5}\right.$ and $\left.10^{6} \mathrm{mf}_{\mathrm{mL}}^{-1}\right)$; in the third experiment, the effect of leaf wetness period was tested by maintaining cowpea plants at $0,6,12,24$ and 48 hours of leaf wetness after the inoculation, and in the last experiment the effect of phenological states was tested by inoculating cowpea plants at the stages of cotyledonal leaf, trifoliate leaves, flowering and pod filling. The highest severity values of disease were observed with the plants inoculated in the flowering phenological state with $10^{6} \mathrm{mf}^{\mathrm{m}} \mathrm{mL}^{-1}$ and six hours of leaf wetness. These parameters can be utilized to establish an inoculation methodology for $R$. solani on cowpea plants under controlled conditions.
\end{abstract}

Key words: Rhizoctonia solani, Thanatephorus cucumeris, Vigna unguiculata, epidemiology, Blackeye bean.

\section{INTRODUÇÃO}

O feijão-caupi [Vigna unguiculata (L.) Walp.] conhecido popularmente como feijão-de-corda, feijão macáçar e feijão-da-colônia é uma cultura que possui uma ampla variabilidade genética, sendo usada para várias finalidades e em diversos sistemas de produção (Freire Filho et al., 2005). O feijão-caupi tem alta qualidade nutricional devido aos seus altos teores de proteína, ferro, fósforo e outros minerais (Iqbal et al., 2006; Kaba et al., 2007; Sprent et al., 2010), o que torna a cultura uma fonte alimentar importante e estratégica para as regiões tropicais e subtropicais do mundo (Ehlers \& Hall, 1997).

No Brasil, o feijão-caupi é explorado principalmente nas regiões norte e nordeste, mas já se encontra cultivado também na região centro-oeste. Na região norte o sistema de cultivo predominante é de baixo aporte tecnológico, com colheita manual e em consórcio com outras culturas como mandioca e milho. Além disso, o uso de sementes de má qualidade e a falta de controle de pragas contribui para a diminuição da produtividade da cultura (Filgueiras et al., 2009).

Uma das principais doenças da cultura na região norte é a mela ou murcha-da-teia-micélica, causada pelo fungo Rhizoctonia solani Kühn [teleomorfo Thanatephorus cucumeris (Frank) Donk] (Nechet et al., 2009). Os sintomas da doença se iniciam nas folhas mais próximas ao solo, onde se observam manchas de formato irregular que coalescem causando necrose e posterior desfolha das plantas, além da adesão das folhas da planta pela teia micelial do fungo. Os 
sinais são as teias miceliais e os microescleródios formados nos tecidos vegetais (Nechet \& Halfeld-Vieira, 2006). Em condições de campo, observa-se desfolha de até $72 \%$ em linhagens de feijão-caupi de porte ereto no ecossistema de cerrado no estado de Roraima (Nechet et al., 2006).

O patógeno apresenta grande diversidade e é composto de 12 grupos de anastomose (GA) geneticamente distintos (Ogoshi, 1987; Cubeta \& Vilgalys, 1997). No Brasil, isolados de $R$. solani associados ao sintoma de mela no feijão-caupi foram identificados como GA-1 (Nechet \& Halfeld-Vieira, 2006). No Brasil, o patógeno também causa queima foliar em outras culturas, como arroz, soja e eucalipto (Fenille et al., 2002; Silveira et al., 2000; Souza et al., 2007). Sua sobrevivência na área por longo período através de estruturas de resistência (escleródios), alta capacidade de saprofitismo e ampla gama de hospedeiros, cultiváveis ou não (Papavizas \& Davey, 1961), faz com que a mela seja uma doença de difícil controle. Além disso, não há fungicidas registrados para a cultura do feijão-caupi, o que torna o uso de cultivares resistentes e a rotação de cultura os métodos de controle mais viáveis.

Para a seleção de genótipos de feijão-caupi resistentes à mela os experimentos devem ser conduzidos em condições favoráveis ao desenvolvimento da doença. A seleção de genótipos de feijão-caupi não é eficaz quando experimentos são conduzidos em campo pois depende do potencial de inóculo do patógeno na área e da freqüência de chuvas. Assim, é necessário definir-se de um protocolo de inoculação, em condições controladas, para desenvolvimento e obtenção de alta severidade da doença, padronizando as condições para a pré-seleção de genótipos de feijão-caupi. Os objetivos do trabalho foram definir o tipo e a concentração de inóculo de $R$. solani, o(s) estádio(s) do feijão-caupi suscetível(is) e o período de molhamento foliar mínimo para o desenvolvimento de máxima severidade da mela em casa-de-vegetação.

\section{MATERIAL E MÉTODOS}

\section{Condução do ensaios}

Os experimentos foram conduzidos em condições de casa-de-vegetação, com temperatura controlada de 28 $\pm 2^{\circ} \mathrm{C}$, utilizando-se os genótipos de feijão-caupi IT86D719 e BR03-Tracuateua, caracterizados previamente como suscetível e resistente à mela (Nechet \& Halfeld-Vieira, 2007). A semeadura foi feita em vasos com capacidade de três L contendo solo desinfestado previamente com fumigante de solo do princípio ativo metam-sódico. Após a emergência foi feito um desbate para manter-se duas plantas/vaso. Durante as avaliações a irrigação das plantas foi feita duas vezes por dia com sistema de aspersão.

\section{Efeito do tipo de inóculo}

Dois isolados de Rhizoctonia solani AGI-1A, previamente caracterizados pela formação ou não de escleródios e por não diferirem em agressividade (Nechet \&
Halfeld-Vieira, 2006), foram semeados em placas de Petri contendo meio de Batata Dextrose Agar (BDA) durante três dias a $25^{\circ} \mathrm{C}$ no escuro para obtenção da colônia. Para o isolado sem formação de escleródios, três discos de micélio obtido da periferia desta colônia foram transferidos para erlenmeyers de $250 \mathrm{~mL}$ contendo $100 \mathrm{~mL}$ de meio líquido Batata Dextrose (BD). Os erlenmeyers foram mantidos em incubadora com agitação orbital (Shaker) a $250 \mathrm{rpm}, 28$ $\pm 2^{\circ} \mathrm{C}$ por 10 dias. Após este período, a colônia obtida foi filtrada em gaze, suspensa em água destilada esterilizada e triturada por 1 minuto utilizando agitador mecânico. Para o isolado com formação de escleródios, discos de micélio obtidos da periferia da colônia base foram depositados em placas de Petri contendo meio BDA e as placas mantidas em incubadora a $25 \pm 2^{\circ} \mathrm{C}$ por 10 dias. Após esse período, foi feita a remoção dos escleródios, adicionando-se $10 \mathrm{~mL}$ de água destilada esterilizada em cada placa, e raspandose a superfície das colônias com um pincel. Todas as duas suspensões foram ajustadas para a concentração de $1 \times 10^{6}$ escleródios $/ \mathrm{mL}$ e $1 \times 10^{6}$ fragmentos de micélio $/ \mathrm{mL}$ para padronizar a quantidade de inóculo e ter como fator de variação apenas o tipo de inóculo.

Plantas de feijão-caupi dos genótipos selecionados foram inoculadas com as suspensões de inóculo + Tween 20 0,05\% (polioxietileno monolaurático) e mantidas por 24 horas em câmara úmida, utilizando-se sacos plásticos umedecidos, em casa-de-vegetação. Após este período, foram mantidas nas condições normais da casa-devegetação. $\mathrm{O}$ delineamento experimental foi o inteiramente casualizado em arranjo fatorial (2×2), dois genótipos, dois tipos de inóculo e cinco repetições, sendo cada repetição um vaso com duas plantas. Como testemunhas foram utilizadas plantas pulverizadas com água destilada + Tween 20 a $0,05 \%$.

\section{Efeito da concentração de inóculo}

A partir da seleção do fragmento de micélio como tipo de inóculo, conforme resultado do experimento anterior, foi avaliado o efeito da concentração de inóculo na severidade da doença. As plantas de feijão-caupi foram inoculadas com as suspensões de $0,10^{3}, 10^{4}, 10^{5}$ e $10^{6}$ fgm $/ \mathrm{mL}+$ Tween 20 a $0,05 \%$ e mantidas por 24 horas em câmara úmida, utilizando-se sacos plásticos umedecidos, em casa-de-vegetação. Após este período, as plantas foram mantidas nas condições normais da casa-de-vegetação. $\mathrm{O}$ delineamento experimental foi inteiramente casualizado em arranjo fatorial (2x5), dois genótipos, cinco concentrações de inóculo e cinco repetições, sendo cada repetição um vaso com duas plantas.

\section{Efeito do período de molhamento foliar}

As plantas de feijão-caupi foram inoculadas com a suspensão de inóculo na concentração selecionada no experimento anterior acrescido de Tween 20 a $0,05 \%$ e colocadas em câmara úmida, utilizando-se sacos plásticos umedecidos, por $0,6,12,24$ e 48 horas. Durante e após 
cada período estipulado, as plantas foram mantidas em condições de casa-de-vegetação. Após as inoculações as plantas do tratamento de período de molhamento foliar de 0 $\mathrm{h}$ foram imediatamente submetidas às condições de casa-devegetação. $\mathrm{O}$ delineamento experimental foi inteiramente casualizado em arranjo fatorial (2×5), dois genótipos, cinco períodos de molhamento e cinco repetições, sendo cada repetição um vaso com duas plantas. Como testemunhas foram utilizadas plantas pulverizadas com água destilada + Tween 20 0,05\% e submetidas aos períodos de 0, 6, 12, 24 e 48 horas de molhamento foliar.

\section{Efeito do estádio fenológico das plantas}

A semeadura dos genótipos IT87B719 e BRS Tracuateua foi feita em intervalos de cinco dias ou dez dias para se obter, na época da inoculação, plantas em quatro estádios fenológicos: de folhas primárias, folhas trifoliadas, com flores abertas e em enchimento de vagens. $\mathrm{O}$ procedimento de inoculação foi o mesmo descrito no experimento anterior com uso de seis horas de molhamento foliar após a inoculação. $O$ delineamento experimental foi inteiramente casualizado em arranjo fatorial $(2 \times 4)$, dois genótipos, quatro estádios fenológicos e cinco repetições, sendo cada repetição um vaso com duas plantas.

\section{Avaliações}

As avaliações foram feitas, semanalmente, após sete dias da inoculação, medindo-se a porcentagem de área foliar lesionada estimada com auxílio da escala diagramática de Van Schoonhoven \& Pastor-Corales (1987). A partir dos dados de severidade calculou-se a área abaixo da curva de progresso da doença (AACPD) (Campbell \& Madden, 1990). Procedeu-se a análise de variância usando o procedimento GLM do software SAS versão 9 (SAS Institute Inc., Cary, USA) e as médias foram comparadas pelo teste de Fisher LSD a $1 \%$ de probabilidade (Nashimoto \&Wright, 2005).

\section{RESULTADOS E DISCUSSÃO}

Não se observou diferença significativa entre os dois genótipos de feijão-caupi quanto à AACPD das plantas quando inoculados com fragmentos de micélio ou escleródios (Figura 1). Entretanto, houve diferença significativa entre os valores de AACPD dos genótipos quando se utilizou fragmentos de micélio como inóculo (Figura 1). Os resultados mostraram a viabilidade do uso de fragmentos de micélio de $R$. solani como inóculo para os experimentos com o patossistema em casa-de-vegetação. A produção de micélio como tipo de inóculo é mais rápido de ser produzido e utiliza menos material e volume de meio de cultura, portanto foi selecionado como inóculo nos experimentos posteriores. $\mathrm{O}$ uso de suspensão de micélio tem sido adotado em metodologias de seleção de genótipos resistentes à mela em feijão (Phaseolus vulgaris L.) (Bautista-Perez \& Echávez-Badel, 2000; Takegami et al., 2004). O micélio tem um papel importante na patogênese de $R$. solani uma vez que inicia o processo de infecção caracterizado pela adesão da hifa e formação de estruturas de penetração no tecido foliar e posterior colonização (Garcia et al., 2006).

No experimento de concentração de inóculo foi observada diferença estatística entre a AACPD dos tratamentos utilizados para ambos os genótipos. Para o genótipo IT86D-719 os maiores valores foram verificados nas plantas inoculadas com as concentrações de $10^{6}(\mathrm{AACPD}=500)$ e $10^{5}(\mathrm{AACPD}=478)$ seguida de $10^{4}(\mathrm{AACPD}=297)$ e $10^{3}(\mathrm{AACPD}=152) \mathrm{fgm} / \mathrm{mL}$. Para a cultivar BR03 Tracuateua, as plantas inoculadas com a concentração de $10^{6} \mathrm{fgm} / \mathrm{mL}$ apresentaram o maior valor de AACPD (425) diferindo estatisticamente dos valores observados para as plantas inoculadas com as concentrações de $10^{5}(\mathrm{AACPD}=329), 10^{4}(\mathrm{AACPD}=164)$ e $10^{3} \mathrm{fgm} / \mathrm{mL}$ (AACPD=135). Para a metade dos tratamentos, observouse diferença estatística entre os genótipos, seguindo a tendência das plantas do genótipo suscetível (IT86D-719) apresentaram maior severidade em relação ao genótipo resistente (BR03 Tracuateua) (Figura 2). Baseado nos resultados obtidos para ambos os genótipos, selecionou-se a concentração de $10^{6} \mathrm{fgm} / \mathrm{mL}$ para se obter maiores valores de severidade da doença.

Observou-se que a severidade da mela não aumentou, progressivamente, em função de maior período de molhamento foliar após a inoculação (Figura 3). Nesse experimento, a resposta de reação das plantas aos tratamentos de molhamento foliar variou de acordo com o genótipo utilizado. Para IT86D-719, observou-se diferença estatística apenas entre a severidade das plantas submetidas

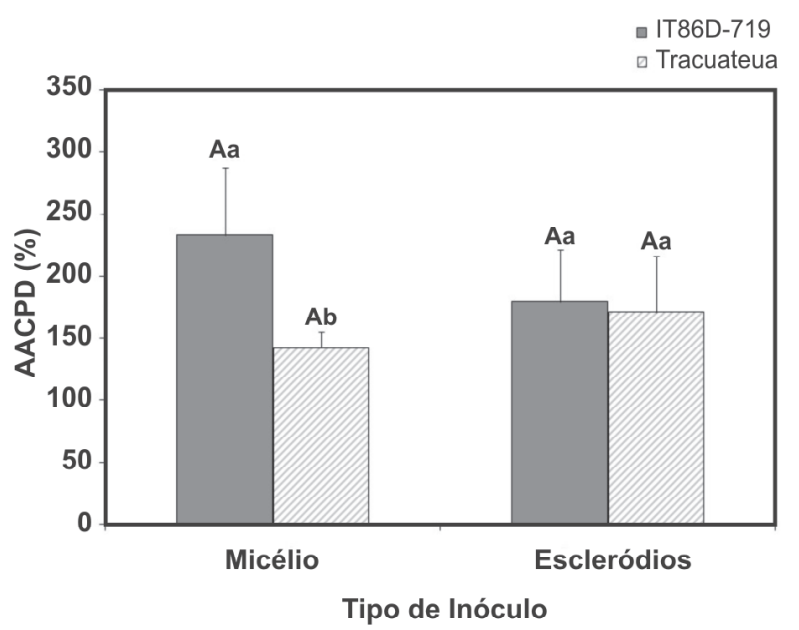

FIGURA 1 - Médias da área abaixo da curva de progresso da doença (AACPD) em plantas de feijão-caupi dos genótipos IT86D-719 e BR 03 Tracuateua inoculadas com escleródios e fragmentos de micélio de Rhizoctonia solani. Médias seguidas pela mesma letra maiúscula entre tratamentos e minúscula entre genótipos não diferem estatisticamente pelo teste de Fisher LSD a $1 \%$ de probabilidade. Barra=desvio padrão. Coeficiente de Variação $=25 \%$. 

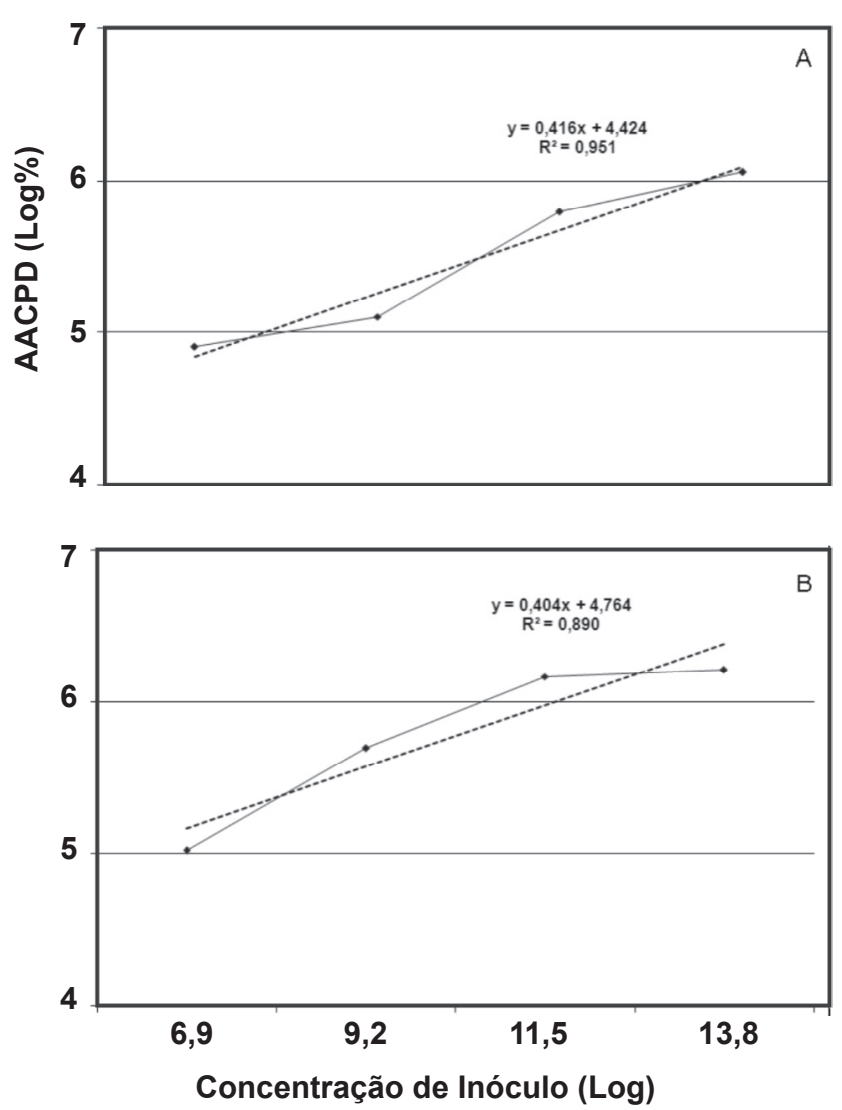

FIGURA 2 - Área abaixo da curva de progresso da doença (AACPD) em plantas de feijão-caupi dos genótipos BR 03 Tracuateua (A) e IT86D-719 (B) inoculadas com as concentrações de $6,9\left(\log 10^{3}\right) ; 9,2\left(\log 10^{4}\right) ; 11,5\left(\log 10^{5}\right)$ e $13,8\left(\log 10^{6}\right)$ fragmentos de micélio de Rhizoctonia solani $/ \mathrm{mL}$. Coeficiente de Variação $=18 \%$.

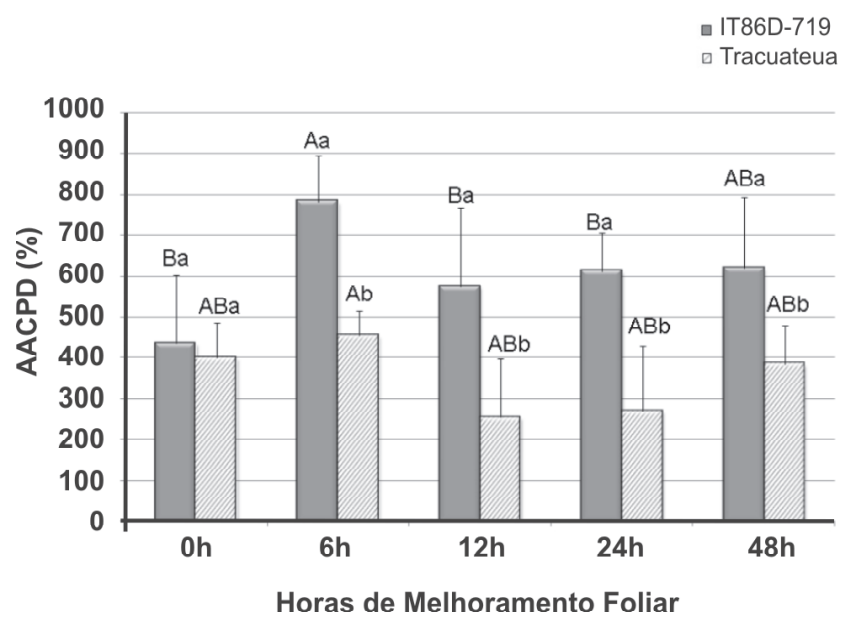

FIGURA 3 - Médias da área abaixo da curva de progresso da doença (AACPD) em plantas de feijão-caupi dos genótipos IT86D-719 e BR 03 Tracuateua submetidas aos períodos de 0 , $6,12,24$ e 48 horas de molhamento foliar após a inoculação de Rhizoctonia solani. Médias seguidas pela mesma letra maiúscula entre tratamentos e minúscula entre genótipos não diferem estatisticamente pelo teste de Fisher LSD a 1\% de probabilidade. Coeficiente de Variação $=25 \%$. a 6 horas $(\mathrm{AACPD}=784)$ e das plantas não expostas a um período de molhamento após a inoculação (AACPD=437). Nos demais tratamentos, os valores de AACPD foram 576 (12 horas), 613 ( 24 horas) e 621 (48 horas). Para BR03 Tracuateua, o valor de AACPD do tratamento de 6 horas de molhamento foliar (456) diferiu estatisticamente da severidade observada nos períodos de $12(\mathrm{AACPD}=255)$ e 24 horas $(\mathrm{AACPD}=271)$. Os demais valores obtidos nesse genótipo foram 400 (0 hora) e 385 (48 horas). Todos os períodos de molhamento foliar utilizados, com exceção do tratamento de 0 hora, permitiram diferenciar a reação dos genótipos. O uso de 6 horas de molhamento foliar após a inoculação foi suficiente para permitir o desenvolvimento da doença em condições de casa-de-vegetação e obter valores altos de severidade. A maioria dos fungos fitopatogênicos requer água livre sobre a superfície do tecido hospedeiro para iniciar o processo de infecção uma vez que a umidade é indispensável para o início do ciclo de infecção (Agrios, 2005). Alguns trabalhos têm demonstrado que em outros patossistemas, o aumento do período de molhamento foliar não está relacionado a uma maior severidade da doença e que a temperatura influencia nesses resultados (Latorre et al., 2002; Kurt \& Tok, 2006).

Observou-se distinção da reação das plantas de feijão-caupi em função do estádio fenológico para ambos os genótipos (Figura 4). Para BR03 Tracuateua, os maiores valores de severidade foram observados nos estádios de flores abertas (E3) $(\mathrm{AACPD}=635)$ e enchimento de vagens $(\mathrm{E} 4)(\mathrm{AACPD}=626)$ seguido do estádio de trifólios (E2) $(\mathrm{AACPD}=222)$ e plântulas $(\mathrm{E} 1) \quad(\mathrm{AACPD}=16)$. Para IT86D-719 observou-se diferença estatística entre a AACPD de todos os estádios. O maior valor foi o do estádio E3 (AACPD=817) seguido de E4 (AACPD=603), E2 $(\mathrm{AACPD}=212)$ e $\mathrm{E} 1(\mathrm{AACPD}=39)$. As plantas inoculadas no estádio 1 apresentaram pequenas manchas que não influenciaram seu crescimento. Os resultados indicam que plantas de feijão-caupi são mais suscetíveis à mela a partir do estádio de flores abertas.

Muitas plantas mostram diferença de reação de resistência de acordo com seu estádio fenológico. Este fenômeno tem sido conhecido como ARR (age related resistance) ou resistência relacionada à idade (RRI) (Panter \& Jones, 2002). A observação mais frequente é o aumento da resistência com a idade da planta. Costa et al. (2007) em estudo similar com o patossistema mela e feijão (P. vulgaris) mostraram que plantas mais velhas são mais resistentes à doença, ao contrário do que foi observado nesse trabalho. Por outro lado, há exemplos de que a suscetibilidade aumenta com a idade da planta, como o observado por Elmer \& Ferrandino (1995) com o patossistema Septoria lycopersici e tomate (Lycopersicon esculentum), sugerindo a perda dos mecanismos relacionados à resposta de defesa da planta neste estádio fenológico. Heath (1994) verificou uma relação de resistência de plantas mais velhas de feijãocaupi às raças 1 e $\mathrm{N}_{2}$ de Uromyces vignae apenas nas cultivares que apresentavam genes de resistência e não nas suscetíveis. 


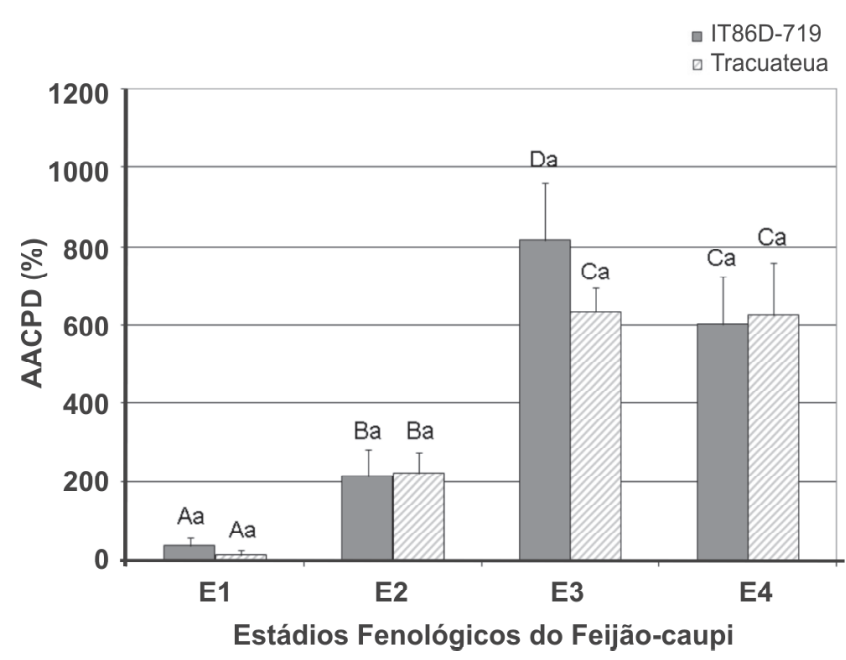

FIGURA 4 - Médias da área abaixo da curva de progresso da doença (AACPD) em plantas de feijão-caupi dos genótipos IT86D-719 e BR03 Tracuateua inoculadas com Rhizoctonia solani nos estádios fenológicos de folhas primárias (E1), folhas trifoliadas (E2), flores abertas (E3) e enchimento de vagens (E4). Médias seguidas pela mesma letra maiúscula entre tratamentos e minúscula entre genótipos não diferem estatisticamente pelo teste de Fisher LSD a $1 \%$ de probabilidade. Barra= desvio padrão. Coeficiente de Variação $=22 \%$.

Neste trabalho a resposta observada foi a mesma tanto para o genótipo resistente BR 03 Tracuateua como para o suscetível IT86D-719.

O uso de um protocolo de condução de experimentos em casa-de-vegetação visando a obtenção de alta severidade da mela do feijão-caupi é um requisito importante para padronização e confiabilidade da seleção de materiais resistentes à doença. A partir dos resultados desse trabalho sugere-se um protocolo para a pré-seleção de genótipos de feijão-caupi em condições de casa-de-vegetação, onde se devem inocular as plantas no estádio de flores abertas na concentração de $10^{6} \mathrm{fgm} / \mathrm{mL}$ e submetidas a seis horas de molhamento foliar após a inoculação para se obter condições favoráveis ao desenvolvimento da mela.

\section{AGRADECIMENTOS}

Os autores agradecem ao Conselho Nacional de Desenvolvimento Científico e Tecnológico - CNPq (Proc. 471038/2006-7) pelo suporte financeiro e o segundo autor pela concessão de bolsa (Proc. 303081/2007-4).

\section{REFERÊNCIAS BIBLIOGRÁFICAS}

Agrios GN (2005) Plant Pathology. 5th ed. San Diego. Academic Press.

Bautista-Perez M, Echávez-Badel R (2000) Methodology for screening common bean resitance to web blight. Journal of
Agriculture of the University of Puerto Rico 84:91-94.

Campbell CL, Madden LV (1990) Introduction to plant disease epidemiology. New York NY. Wiley.

Costa GR, Lobo Junior M, Café-Filho AC (2007) Influência da idade da planta no desenvolvimento da mela do feijoeiro comum. Fitopatologia Brasileira 32 (Supl.):295.

Cubeta MA, Vilgalys R (1997) Population Biology of the Rhizoctonia solani Complex. Phytopathology 87:480-484.

Ehlers JD, Hall AE (1997) Cowpea (Vigna unguiculata L. Walp.). Fields Crop Research 53:187-204.

Elmer WH, Ferrandino FJ (1995) Influence of spore density, leaf age, temperature, and dew periods on Septoria leaf spot of tomato. Plant Disease 79:287-290.

Filgueiras GC, Santos MAS dos, Homma AKO, Rebello FK, Cravo MS (2009) Aspectos Socioeconômicos. In: Zilli JE, Vilarinho AA, Alves JMA (Eds.) A cultura do feijão-caupi na Amazônia Brasileira. Boa Vista. Embrapa Roraima. pp. 23-58.

Fenille RC, Souza NL, Kuramae EE (2002) Characterization of Rhizoctonia solani associated with soybean in Brazil. European Journal of Plant Pathology 108:783-792.

Freire Filho FR, Lima JA de A, Ribeiro VQ (2005) FeijãoCaupi. Avanços Tecnológicos. Brasília. Embrapa Informação Tecnológica.

García VG, Onco MAP, Susan VB (2006) Review. Biology and Systematics of the form genus Rhizoctonia. Spanish Journal of Agricultural Research 4:55-79.

Heath MC (1994) Genetics and cytology of age-related resistance in North American cultivars of cowpea (Vigna unguiculata) to the cowpea rust fungus (Uromyces vignae). Canadian Journal of Botany 72:575-581.

Iqbal A, Khalil IA, Ateeq N, Khan MS (2006) Nutritional quality of important food legumes. Food Chemistry 97:331-335.

Kaba O, Yilmaz E, Ozmerzi A, Akinci I (2007) Some physicals and nutritional properties of cowpea seeds (Vigna sinensis L.). Journal of Food Engineering 79:1405-1409.

Kurt S, Tok FM (2006) Influence of inoculum concentration, leaf age, temperature, and duration of leaf wetness on Septoria blight of parsley. Crop Protection 25:556-561.

Latorre BA, Rioja ME, Lillo C, Munoz M (2002) The effect of temperature and wetness duration on infection and a warning system for European canker (Nectria galligena) of apple in Chile. Crop Protection 21:285-291.

Nashimoto K, Wright FT (2005) Multiple comparison procedures for detecting differences in simply ordered means. Computational Statistics and Data Analysis 48:291-306.

Nechet KL, Halfeld-Vieira BA (2006) Caracterização de isolados de Rhizoctonia spp., associados à mela do feijão-caupi (Vigna unguiculata), coletados em Roraima. Fitopatologia Brasileira 31:505-508.

Nechet KL, Halfeld-Vieira BA (2007) Reação de cultivares de feijão-caupi à mela (Rhizoctonia solani) em Roraima. Fitopatologia Brasileira 32:424-428.

Nechet KL, Halfeld-Vieira BA, Boari AJ, Nascimento JF (2009) Doenças. In: Zilli JE, Vilarinho AA, Alves JMA (Eds.) A cultura do feijão-caupi na Amazônia Brasileira. Boa Vista. Embrapa 
Roraima. pp. 245-270.

Nechet KL, Vilarinho AA, Halfeld-Vieira BA (2006) Reação de Genótipos de Feijão-Caupi a Mela (Rhizoctonia solani) em Três Ecossistemas de Roraima. Anais, I. Congresso Nacional de FeijãoCaupi- CONAC. Teresina PI. (Resumo expandido)

Ogoshi A (1987) Ecology and pathogenicity of anastomosis and intraspecific groups of Rhizoctonia solani Kuhn. Annual Review of Phytopathology 25:125-143.

Panter SN, Jones DA (2002) Age-related resistance to plant pathogens. Advances in Botanical Research 38:251-280.

Papavizas GC, Davey CB (1961) Saprophytic behavior of Rhizoctonia in soil. Phytopathology 51:693-699.

Silveira SF da, Alfenas AC, Ferreira FA, Sutton JC (2000) Characterization of Rhizoctonia species associated with foliar necrosis and leaf scorch of clonally-propagated Eucalyptus in
Brazil. European Journal of Plant Pathology 106:27-36.

Souza EC, Kuramae EE, Nakatani AK, Basseto MA, Prabhu AS, Ceresini PC (2007) Caracterização citomorfológica, cultural, molecular e patogênica de Rhizoctonia solani Kühn associado ao arroz em Tocantins, Brasil. Summa Phytopathologica 33:129136.

Sprent JI, Odee DW, Dakora FD (2010) African legumes: a vital but under-utilized resource. Journal of Experimental Botany 61:1257-1265.

Takegami JC, Beaver JS, Godoy-Lutz G, Echávez-Badel R, Steadman JR (2004) Inheritance of web blight resistance in common bean. Journal of Agriculture of the University of Puerto Rico 88:45-54.

van Schoonhoven A, Pastor-Corales MA (1987) Sistema estándar para la evaluación de germoplasma de frijol. Cali. CIAT.

TPP 114 - Recebido 3 Maio 2010 - Aceito 13 Janeiro 2011 Editor de Seção: Nilceu R.X. Nazareno 